\title{
Research on the Application of Football Classic Tactic Teaching System in Football Compulsory Course in High Normal Colleges
}

\author{
Haitao Wang* and Ying Xu
}

Department of Physical Education, Huaibei Normal University, Huaibei, Anhui, People's Republic of China

\begin{abstract}
Ased on the National Education Ministry's "Main Courses Teaching Guidance Outline For College Physical Education Undergraduate Course", this study analyzes some main issues in the football tactic teaching in sports education professional. Combining the present high normal colleges and universities physical education teaching, the study designs and develops the football tactic teaching system with modern multimedia technology. At last, the author implements a comparative experiment in order to form a high efficiency tactics teaching process in the limited teaching hours and to improve students' tactical ability to lay a good foundation for future for students in football teaching and training work.
\end{abstract}

Keywords: Applied research, football compulsory course, multimedia technology, tactics teaching.

\section{INTRODUCTION}

Football course is a required course for physical education major in normal universities. As key teaching contents in football compulsory course, football tactic teaching is not simple fixed routine drills. It is more likely improvement for students on the macro level understanding of football in the basis of comprehensive football technique. But there are two main problems existing in the teaching process. On the one hand, tactic teaching of football need multi-person scene demonstration, there is a lot of inconvenience for independent teaching football teacher. On the other hand, through classroom theory teaching, simulation drawing or tactical disk demonstration to carry on the teaching, students can only passively accept some theory indoctrination, lack of basic subjective initiative.

The rapid development of interactive information technology based on multimedia technology provides the opportunity for changing the tactic teaching mode of football course. Multimedia technology, with its intuitive, integrated, interactive features, will expand the capacity of classroom teaching, improve teaching efficiency; change the abstract to the concrete, not only conforms to the law of students' cognition, but also reduces the difficulty of the thinking of the students; to stimulate students interest in learning, is more conducive to train the innovative ability of students.

This paper designed football tactic teaching system and has conducted the experimental study in practice teaching, combining the application characteristics of the multimedia technology and the characteristics of football tactics teaching. That is to say, it integrates classic football game in personal, local, overall tactical paradigm with multimedia technology, and fusion of animation analysis, decomposition demonstration, scene display and many other football tactics teaching mode. This teaching method has basic multimedia characteristics, also gives detail animation by analyzing collected data of classic video game with tactical content taught. In the content of the configuration, the teaching system will apply the requirements of the syllabus and highlight the focus of teaching in allocation of resources. According to variability of on-the-spot use of football tactics, it can show the classic tactical material in a short period of time in the multi angle, multi form and multi range, in different forms of application mode, decomposition of some complex tactical information completely, reduce the cognitive burden of students. At the same time the system selected the world cup, European Cup, Champions League football classic match material, try to attract students' eye, stimulate students' highly conscious learning enthusiasm.

\section{RESEARCH OBJECT AND RESEARCH METHODS}

This research focuses on students of the 2009 grade football course, Sports Institute, Huaibei Normal University. 5 methods are employed in the article.

\subsection{Literature Review}

According to the needs of this research, access to relevant information on teaching of football tactics, collect the syllabus football course of all higher normal colleges, collect and edit classic football game video, and multimedia data.

\subsection{Experimental Research}

In order to verify the validity and feasibility of the classic tactics teaching system applied in teaching of football tactics analysis, this study randomly selected four classes in seven as the experimental object, in Sports Institute, 2009 sports education, Huaibei Normal University. Before, there was no significant difference between the sample group and control group. Then apply portable multimedia display equipment, com-pare the groups on application of football classic tactical analysis teaching system and conventional tactics teaching methods. 


\subsection{Mathematical Statistics}

In the application of classical tactical analysis teaching system, use the SPSS software to the collected individual students, local and overall tactics for the score, and the tactical theory test and other post test data analysis, to evaluate the application effect of multimedia technology in football compulsory tactics teaching course.

\subsection{Questionnaire Survey}

Before the teaching design, we conducted a questionnaire survey on experts in some normal universities of China engaged in football teaching and with a senior professional title. The investigation content mainly focus on the feasibility of the application of multimedia technology in the teaching of football tactics, analysis and evaluation standard, tactical standard and theory examination practice, general course main tactics content determination and so on.

\subsection{Classroom Observation}

We live in a huge and complex system of the world. The world is complex, its elements are complex, and it has heterogeneity. Its structure is complicated, not only on the permutation and combination of the elements, but also on the cell, tissue, organism, population and other complex hierarchy. Children's motor skill disorder also have many different types, with various symptoms. For example, according to the completion of motor skill involved muscle groups. Motor skill can be divided into gross motor skill and fine motor skill. Gross motor skill is those skill completed by large muscle groups, such as running. Fine motor skill is those completed by small muscle groups, such as writing. Therefore data of diagnosis expert system based on children motor skill disorder is complicated.

\section{APPLICATION AND DATA ANALYSIS}

Multimedia Teaching System is used in the practice as the following:

\subsection{Guiding Ideology of Multimedia Classic Tactic Analysis Teaching System}

According to the basic requirement of the Guidance Outline of main course teaching for college sport education undergraduate major, combining with the teaching rules of football teaching and the characteristics of multimedia technology in football tactic teaching, making full use of the advantage of the information bearing and expression of multimedia equipment in the whole teaching process, mobilize the initiative, the enthusiasm of the students. Let the students imitate the classic case contained in the tactical teaching system, make students unconsciously get into of tactical tactical situations, do more exercise, so as to achieve a firm grasp of learning content, subjectively to apply the tactics.

\subsection{Application Characteristics Of Multimedia Classic Tactic Analysis Teaching System}

Large information, strong excitant. The amount of information of all kinds of teaching media teaching content is different; the stimulation intensity on the brain is different. The traditional tactic teaching use only a verbal stimuli or student decompose in theory teaching, much different with true scene in the classic tactic analysis teaching system. The teaching system can be applied from different angles and in various speed in the explanation of pictures, with flash slow movement decomposition demonstrates, to get strong stimulating quantity. Relatively speaking, the transformation of absorption is more, the students learn more.

A higher frequency to arouse students' reaction. Arousal response refers to the stimulation response of learners. Different teaching patterns are different in frequency and form of causing students response. The traditional teaching mode emphasizes the teacher's classroom teaching or simple demonstration, students can only passively accept, not be able to participate. Therefore, the teacher can not evaluate whether the receptor get it. Classic tactic analysis teaching system with multimedia gives students more opportunity to participate. These video are collection of impressive games they have seen. By virtue of their own memory traces, with tactical theory concept learning, they are positive to participate in the tactical analysis and learning process, students' enthusiasm is high. Interested things have higher arousal response frequency; it is more beneficial to the tactics of learning.

Easy control of the learning process. Controllability refers to ability of selectively reproducing required content in the teaching process. Comparing with the TV live broadcast, watching games, classic tactic analysis teaching system has more flexibility, it can selectively reproducing teaching content. The system can make teachers liberated from the complexity of labor of demonstration and representation; teachers can easily control teaching process and improve the teaching. Of course, the teachers' teaching is more relaxed.

\subsection{Implementation of Multimedia Classic Tactic Analy- sis Teaching System}

In this experiment, using the method of cluster sampling, a total of 116 people of four groups of 2009 will participate in the teaching experiment, they were divided into experimental group and the control group respectively for teaching experiment. The experimental group and the control group respectively adopt different mode of teaching tactics teaching. The control group adopts traditional teaching to learn theory, and then do grouping exercise. The experimental group adopt multimedia classic tactic analysis teaching system, the teaching process include preparation before class - class multimedia presentation - practice course to create situations students into the situation - students' actual combat demo.

Preparation before class refers to that before the teaching content of single tactics, put forward under-class request to the student, and examined in the class. The concrete implementation is that the use of modern network equipment, videos of tactical teaching content uploaded to Youku, Tudou and other network storage space, to facilitate the sharing of tactical teaching content. Let the students understand tactical course contents in advance and the tactical thought, in the mind they have a preliminary framework, in specific classroom learning they will quickly enter the teaching. From the effect, network preview significantly better than the book preview. Videos on network sharing course ware have different effect. Network preview course ware video screen shot as in Fig. (1). 


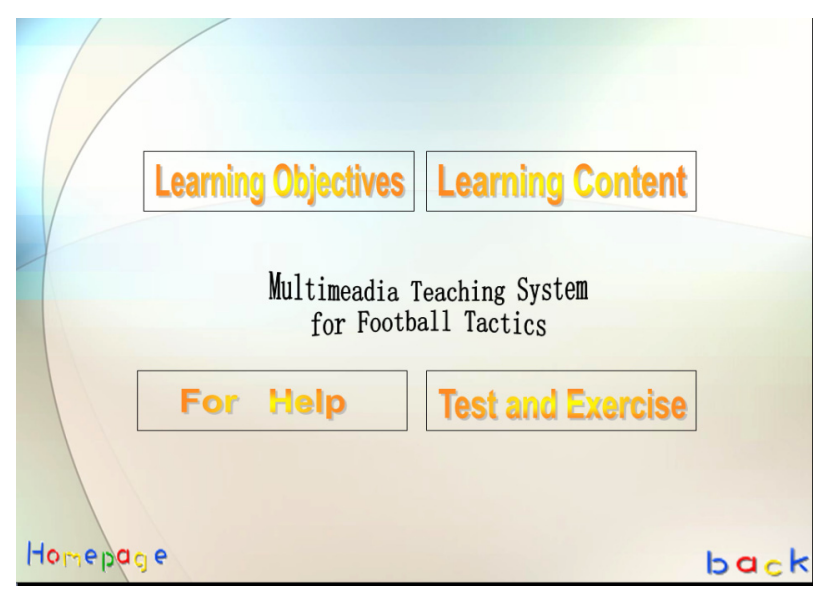

Fig. (1). Network preparation.

After preparation before class, in the specific tactics teaching, teachers use multimedia display equipment to analyze edited video, to give detailed explanation, demonstration.

First of all, to enable students to understand the tactical concepts and types (Tactical classification interface as shown in Fig. (2). By demonstration, let the students understand specific meaning of tactic content. Because the flash animation is not so complicated as video, students can concentrate in the animation flashing icon, it is easy for students to clarify ideas. At the same time, flash can be quick and repeated playback, can carry out continuous visual impact on students, it is more convenient with continuous repeating scene and deep understanding. Animation interface as shown in Fig. (3).

Secondly, analyze tactics after definition and classification of specific tactics. Combined with specific classical tactical video, using pause, slow, playback function of a portable multimedia display device, analyze the edited tactics, including the tactical application forms, attention elements, the suitable scene for the application and so on. Take kicking-wall type one-two as an example, after concept explanation and flash animation, analyze the method of tactics. One -two means that with the players pass, don't stop, direct the ball to receiver. Analyze it with pictures. Then introduce the successful elements of one-two, such as the passer and receiver into a triangle, to pass on the ground, pass opportunity

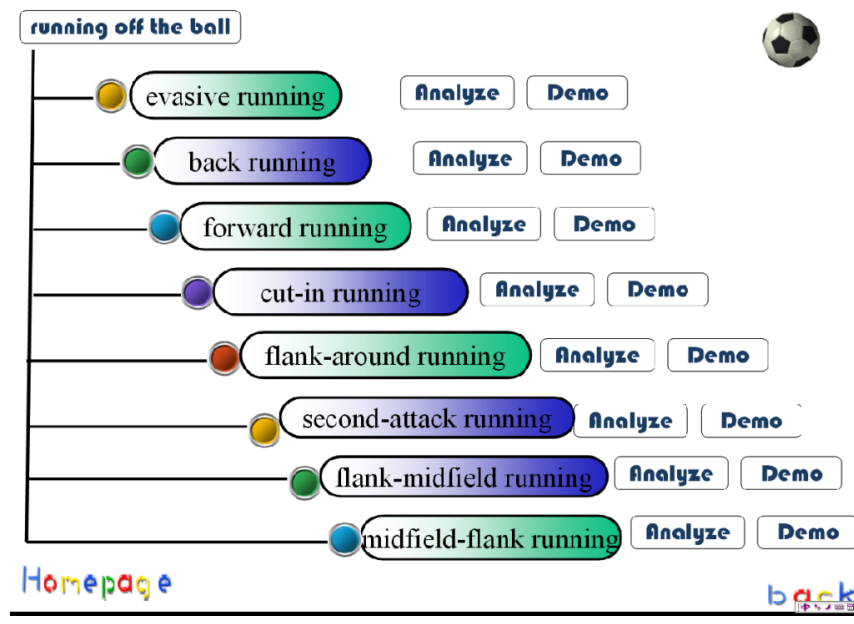

Fig. (2). Tactic classification.

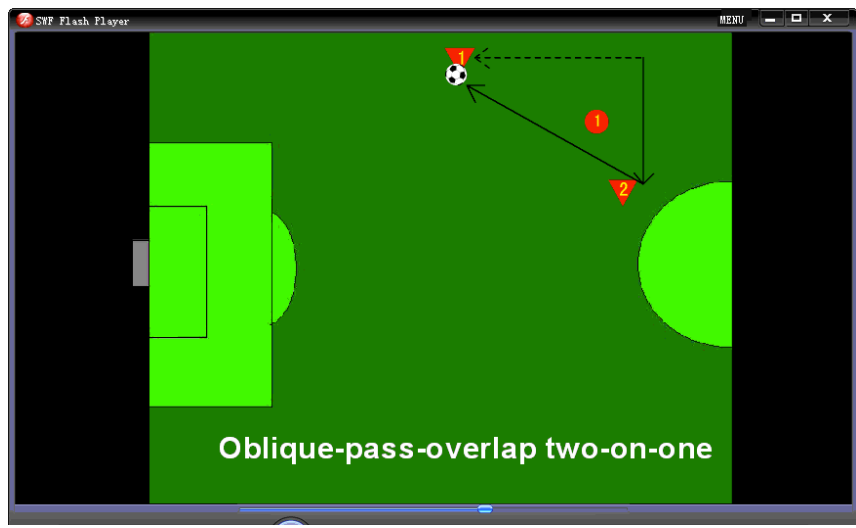

Fig. (3). One-two flash demonstration.

should be accurately grasped and so on. Analyze these with the world cup pictures, and scene of Messi and Alves doing one-two on The UEFA Champions League. At last present various one-two scene. Let students do not rigidly adhere to a simple picture flash demonstrates in tactical exercises, know the creativity in the concrete application of the tactics form, improve the ability of self tactical application. Fig. (4) is interface of analyzing kicking wall type one-two.

After explaining and analysis by the application of multimedia course ware on teacher class, teachers need to create

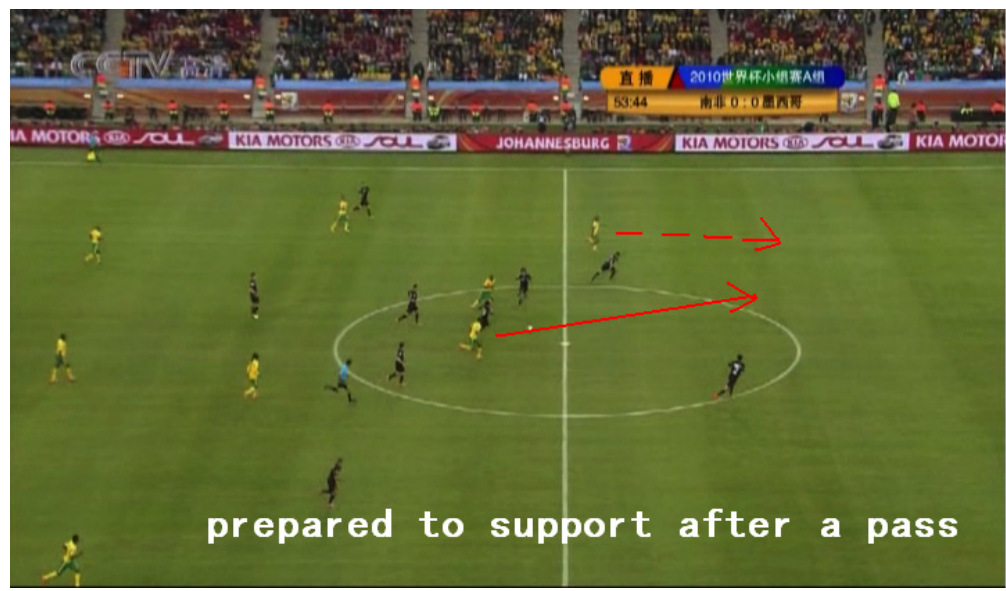

Fig. (4). One-two video analysis. 
Table 1. Evaluation methods and indexes.

\begin{tabular}{|c|c|c|c|}
\hline First Index & Second Index & Method & Evaluation Criterion \\
\hline \hline Tactics theory & Knowledge & Full mark of 100 \\
Description & close-book examination & (Independent scoring by 3 teachers) \\
\hline Learning enthusiasm & $\begin{array}{c}\text { Learning attitude } \\
\text { Learning interest }\end{array}$ & $\begin{array}{c}\text { questionnaire survey } \\
\text { classroom observation }\end{array}$ & Five-level attitude scale \\
Tactics capacity & $\begin{array}{c}\text { Individual tactics } \\
\text { Partial tactics } \\
\text { Overall tactics }\end{array}$ & Process record evaluation & Corporation frequency \\
\hline
\end{tabular}

Table 2. Evaluation on learning effect.

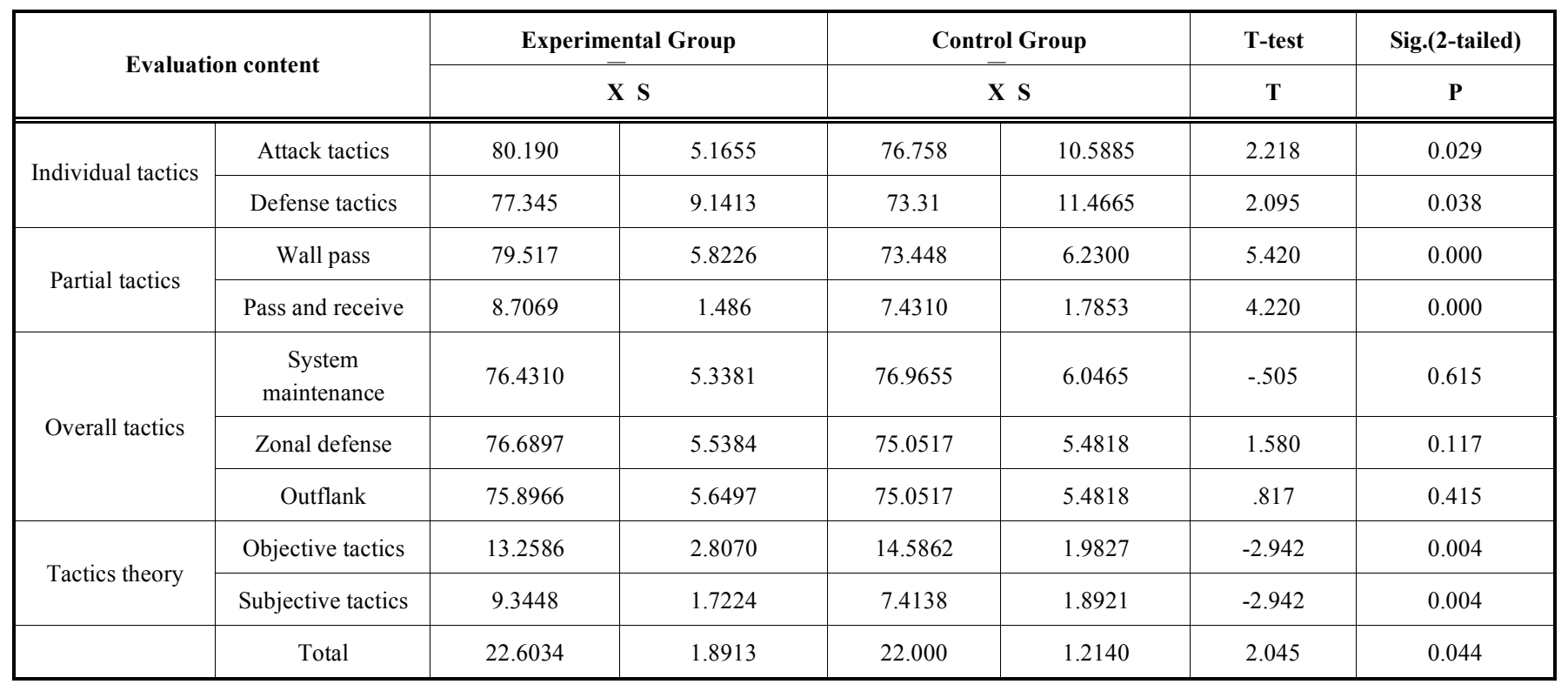

tactic application scene for specific practice. These need to imitate with impression of classic tactic examples. For example, one-two need two people in triangle, the wall is not fixed, pass ball on the ground, suitable opportunity. Teachers should propose relative requirements in the organization of exercises for students. Combined with the design of the course ware, make students feel video analysis scene, thus make correct tactical response, achieve the purpose of the students into the situation and enhancing the teaching effect.

The last stage is the actual combat drills of students. Students do the teaching competition drill, it can apply technology of football, as well as tactical application ability. Through collective cooperation and participation of all students' efforts, comprehensive application ability on tactical content of students will be improved. The personal, local, integrate tactical ability, with the combination of different scenes in the game, random application of tactical content, these help to achieve proficiency in tactical grasp.

\subsection{Evaluation System and Data Analysis}

The main contents of the evaluation of the teaching experiment contain the students' interest and love for football tactics class, skilled degree of tactical coordination, on-the- spot application ability of tactical practical, theory course content examination. Through on-site classroom video playback statistics, classify record of tactics teaching content of football course of physical education major. Personal tactics,local tactics, integrate tactics and tactical theory on evaluation are designed specially forms to record and analyze. Specific evaluation and indexes see Table $\mathbf{1}$ and $\mathbf{2}$.

\subsection{Result}

Multimedia classic tactic analysis teaching system can promote the football course tactical learning process.

\subsubsection{Improve Students' Interest on Football Tactic Con- tent}

Learning interest is the source power of students to actively participate in football activities. Test before experiment shows that when only a few students play football experimental group students have much more interest in learning process of football tactics. Because the designed tactics course ware is those classic football game that sports major students like, with decomposition analysis to specific animation, students can better understand the meaning of tactics, reduce the cognitive difficulty, improve teaching effect. In- 
teractive exercises make students have a great sense of achievement in the physical behavior of experience. Through the concrete classroom observation, students have more tactics teaching requirements than former students, students often discuss with each other to complete situation tactical coordination in course ware. And in control group, there are also individual students require more teaching competition, but because of the understanding of tactics, cannot be very good to complete the tactical coordination, this cause the learning interest is not high.

A questionnaire at the end of football course show that $80 \%$ of the students in experimental group said they will often take part in football activities, this figure increases the proportion of $64 \%$ than former students. In the control group this figure is $75 \%$, increased by $56 \%$. These data demonstrate that the application of multimedia technology in teaching of football tactics improves the students' interest in learning, promotes the students' learning enthusiasm.

\subsubsection{Students Improve the Comprehension of Tactic Con- tent, Enhance the Ability of Application}

The two groups conduct different tactic learning. The experimental group and the control group students show different tactical ability embodied in the teaching game. Personal tactic ability is related with time length of learning football, as well as the basic skills and techniques. In the accumulation of experience, individual tactical learning needs long time combat experience. So in the individual tactical execution, there are obvious difference between students who played the ball more time and the less. Those who played more, show outstanding ability and skills, they have fast and accurate judgment and position selection. In the homogeneity test of variance in individual tactics, homogeneity of variance reflects the students' individual the uneven tactics ability. But as the experimental group and the control group were measured before the experiment, it says there is no significant difference between two groups in the investigation of contacting football. From Table $\mathbf{2}$ we can draw the conclusion, after application of multimedia tactic teaching, the experimental group and the control group in personal attack and defense $\mathrm{T}$ test values were 2.218 and 2.095. The two groups have different grasp on tactic learning.

In the tactic cooperation learning, for the students different ability, or they seldom play football, bad habit of tactics, some students caused negative traction in overall tactic learning. They do not believe classmates lacking ability, hesitate to pass ball, to cover, become passive in tactic learning. To keep the whole formation, routines attack as well as regional defense, they have not enough reaction. But football is a team sport, effect will be weakened if each link has the problem. So the weak and the strong form a mutual restriction. Especially most students never play football before they start football course, the $\mathrm{T}$ value of several items has no obvious variance in the final tactic learning effect.

In the local tactical coordination ability, the experimental group perform much better than the control group. In teaching games, the control group complete oblique direct twoone and direct oblique two-one. The experimental group complete all five kinds of two-one cooperation, especially difficult kick wall two-one and reverse two-one. From the evaluation tables of tactic cooperation ability of the two groups, in the two games the experimental group complete cutting cooperation 505 times, two-one cooperation average 79.51 , the control group complete cutting cooperation 431 times, two-one cooperation average 73.44 , local tactic test cutting $\mathrm{T}$ value is 4.2 , two-one $\mathrm{T}$ value is 5.4. Statistical data analysis shows that evaluation index and the comprehensive scores of the experimental group are higher than that of the control group, shows that the application of multimedia technology in local tactic teaching effect is remarkable for students of local tactic ability teaching.

\subsubsection{Effect Improved in the Students Learning Tactics Theory}

From the data in Table 2 we see, in the objective question answering the control group is better than the experimental group, in the subjective question answering the experimental group is better than the control group, in tactic theory the the experimental group is higher than the control group. To summarize the whole process of experiment teaching, there are several reasons for this situation. In the teaching tactics theory course, the control group used the traditional teaching method of teaching, teachers lecture focus on the textbook content, this accords with traditional learning method of students, and the paper test. But in the subjective content, the experimental group is higher than the control group. This thanks to a deep impression on students of the teaching content of classic tactic learning system. They can play the subjective initiative in the theory exam, can clearly stated learning tactics form, and design course of football tactic learning with the positive use of the basic knowledge. It is much different with the control group. In the evaluation of total score in the experimental group, the mean score of tactic theory is 22.6 , the control group is 22.0. Independent samples $\mathrm{T}$ value of 2.045 shows that the experimental group and the control group are different in theory learning, the experimental group is higher than the control group. Comparison of performance comprehensive conclusion of subjective and objective achievement of the theoretical course, the application of multimedia classic tactic teaching system has a positive effect on football tactics theory.

\section{CONCLUSION}

Based on the above, we have the following three conclusions:

It is feasible to apply multimedia tactic technology to conduct tactic teaching in the football course of higher normal colleges. Design and development of football classic tactic teaching system has opened up new ideas for football course tactics teaching with multimedia teaching.

Application of multimedia technology on the football course tactic teaching can effectively improve students' level of tactical theory, develop students' tactical thinking ability and tactical initiative, enhances students imagery cognitive ability and cognitive abilities on the football tactics, so as to improve the development of students' comprehensive quality.

The teaching effect of multimedia technology on football course tactic teaching is superior to the traditional tactic 
teaching. Not only the teacher teaching become easy, but students in the learning process exhibited higher learning interest and enthusiasm. This shows that the application of multimedia classic tactic teaching system has a very good effect on improving the students' interest in learning and enhancing the students learning content attention.

\section{CONFLICT OF INTEREST}

The authors confirm that this article content has no conflict of interest.

\section{ACKNOWLEDGEMENTS}

This work is supported by "the Ministry of education of Humanities and Social Science project" Foundation of China under grant No.14YJC890026; " the Anhui Philosophy and Social Science Planning Program" Foundation of China under grant No.AHSKQ2014D34.

\section{REFERENCES}

[1] Wallian, N., \& Chang, C. W. "Semiotics of motor ac tion and language activities: to an epistemology of the co-constructed team sports knowledge", In J. F. Gréhaigne (Ed.), Game configurations. Debate of ideas and learning in football and team sports, 2007,pp. $145-164$
[2] Kolyperas, D. Corporate and Social Responsibility in Professional Football Club Organizations, University of Stirling, 2012

[3] Panton, M. Football and Corporate Social Responsibility. Birkbeck Sport Business Centre, 2012,5, No. 2.

[4] Blumrodt, J., Desbordes, M. and Bodin, D. Professional "Football Clubs and Corporate Social Responsibility", Sport, Business and Management: An International Journal, 2013, 3, pp. 205-225.

[5] Zghibi, M., Sahli, H., Bennour, N., Guinoubi, Ch., Guerchi, M., \& Hamdi, M. The Pupil's discourse and action projects: The case of third year high school pupils in Tunisia. Creative Education, 2013,4 , pp. $165-171$.

Cannon,T,\&Hamil,S.Reformingfootball'sboardrooms.InS.Hamil,J. Michie,C.Oughton,\&S.Warby(Eds.),Football in the digita lage, 2000 , pp.36-54

[7] Carroll,A.B.Corporate social responsibility, Business and Society,1999,38(3),268Á295.

[8] Anagnostopoulos, C. From Corporate Social Responsibility (CSR) to Club Stakeholder Relationship (CSR): The Case of Football. The Social Responsibility Research Network Constitution, 2011, No. 3, pp.14-17.

[9] Manchester City Football Club Manchester City Annual Report 2012-13 [Online]. http://content.mcfc.co.uk/ /media/Files/Annual Report/MCFC_AR.pdf

[10] Hamil, S., Walters, G. and Watson, L. The Model of Governance at FC Barcelona: Balancing Member Democracy, commercial Strategy, Corporate Social Responsibility and Sporting Performance. Soccer \& Society, 2010,11, 475-504

[11] Wallian, N., \& Gréhaigne, J.F. To a semio-constructivist approach in motor learning. In G. Carlier (Ed.), If we spoke about the pleasure of physical education teaching,2004, pp. 167-179.

Received: September 22, 2014

Revised: November 30, 2014

Accepted: December 02, 2014

(C) Wang and Xu; Licensee Bentham Open.

This is an open access article licensed under the terms of the Creative Commons Attribution Non-Commercial License (http://creativecommons.org/licenses/by-nc/3.0/) which permits unrestricted, non-commercial use, distribution and reproduction in any medium, provided the work is properly cited. 